\title{
Support for obesity policy: The effect of perceptions of causes for obesity and national identity in Canada
}

\author{
Ryan Lange*, Guy Faulkner \\ Faculty of Kinesiology and Physical Education, University of Toronto, Toronto, Canada; \\ *Corresponding Author: ryan.p.lange@gmail.com
}

Received 6 July 2012; revised 10 September 2012; accepted 16 October 2012

\begin{abstract}
Interventions in Canada to address obesity have largely been limited to individual-level change through education rather than a population-level public policy approach. Little is known about obesity policy support in Canada, and substantial national variation in obesity policy support prevents direct transferability of these policies among nations. Our study recruited 521 young adults for an online survey through leaflets and flyers. We investigated how respondents' demographics, health characteristics, political attitudes, beliefs regarding causes of obesity, and national identity affected their support for obesity policy. Results showed that there is high support for many obesity policies among Canadian young adults. Including Canadian national identity in regression models was significant in explaining obesity policy support beyond the combined effect of other predictors. Further exploration of national identity, in Canada and elsewhere, has implications for understanding obesity policy support that might assist policy makers in making more informed decisions in addressing obesity.
\end{abstract}

Keywords: Obesity; Policy; National Identity; Canada; Opinion; Government

\section{INTRODUCTION}

\subsection{Background}

The incidence of obesity is high in Canada and its prevalence is increasing [1,2]. Obesity is related to various chronic diseases, such as cardiovascular disease, diabetes, and hypertension, but also less tangible factors leading to reduced quality of life and self-esteem [3,4]. Obesity's increasing impact on the daily lives of Canadians makes obesity a public health issue worthy of political and societal attention in Canada [5]. Current approaches consist primarily of health promotion and education campaigns, with fewer strategies explicitly addressing community and environment infrastructure [6]. Educationbased approaches that depend on individual-level change have not been effective in addressing the obesity problem. Canada requires multi-level population approaches to bring about widespread change to upstream structural factors related to the environmental, social, and economic influences on obesity [7]. Change to these upstream factors can be brought about through the broad influence of public policy [8]. Although the government approves and enforces policy, the public may perform critical roles in inspiring policy, advocating for issues to be given political consideration, and supporting (or not) policy implementation. It is of interest then to study the factors that affect public support for obesity policy.

\subsection{National Variation in Policy Support}

There is national variation in perceptions regarding how obesity should be addressed. One salient example of this variation is manifested in support for obesity policy. In the European Union (EU), Suggs et al. looked at policy support for addressing childhood obesity in each EU country individually [9]. They found high consistency in the relative ranking of policies among countries, where the top three supported policy optionsmore physical activity in schools, diet and exercise education for children, and restricting food and beverage advertisements aimed at children-were the same among different regions of the EU. It is remarkable that countries with such different cultural beliefs, obesity prevalence rates, and economic and political contexts share preferences in how to address obesity. However, the absolute support for each policy showed high variation at the level of the individual country. Support for greater physical activity in schools ranged from 11.6 percent in Spain to 68.9 percent in Sweden, with other countries spread out evenly within this range around a mean of 30.5 percent. Variation also existed in how each country ranked relative to other countries in their absolute support for the obesity policies (e.g., Poland was fourth 
in the EU for supporting physical activity in schools, 28th in supporting diet and exercise education for children, and 18 th in restricting advertisements aimed at children). This variability in policy support suggests that in spite of general consensus on which obesity policies are important, there may be key differences in the feasibility of implementation of these policies depending on the country.

\subsection{Policy Support in Canada}

There has been little research on obesity policy support in Canada, and existing research focuses on childhood obesity. For example, Morin et al. found that gender and education have an effect on the types of childhood obesity prevention strategies that Québécois parents would prefer [10]. The greatest preference came for physical and nutrition education programs in childcare settings and measures that would allow employed parents more time to cook and engage in physical activity with their children. Another study by Potestio et al. in Calgary, Alberta described how parents' demographics explained differences in their perceptions of the causes of childhood obesity and methods of prevention [11]. People classified as obese were more likely to support health policy prevention measures than the nonobese. Factors like gender, parental status, and education level, however, were not significant predictors of these policy measures. To our knowledge, no study has looked at obesity policy research in Canada beyond childhood obesity policy. This is a gap that needs rectifying in order to inform Canadian policy development.

\subsection{Attribution Theory}

A common approach for explaining obesity policy support in general that may explain its national variation is attribution theory. Attribution theory, as proposed by Heider, suggests that people make sense of behaviours through understanding the causes of the behaviours [12]. It puts forward that behaviour can be attributed to factors that are internal or external, where internal factors are within a person's control (e.g., too lazy to walk) and external factors are outside of a person's control (e.g., no sidewalks for walking) $[13,14]$. Weiner's expansion of this theory focuses on controllability, which determines how much of a behaviour or condition is voluntary [15]. The key implication of this theory is that the more obesity is attributed to internal, controllable factors, the less likely people are to support certain types of policy that would help the obese [16]. Support for this trend is found in many contexts: attributing poverty to choice leads to less support for welfare programs, associating crime with personal traits results in more severe punishments, and believing people have control over acquiring
HIV/AIDS reduces intentions to help them [17-19].

Several studies have used attribution theory to explain obesity policy support in general. In the UK, Chambers et al. showed that causes of obesity reflecting varying degrees of individual control influence support for obesity policy [20]. In agreement with attribution theory, believing obesity is caused by over-availability of unhealthy foods predicted higher policy support. However, attributing obesity to lack of individual responsibility predicted increased support for child-focused policies. This finding stands in contrast to attribution theory, indicating that obesity policy support is more complex than attribution theory predicts. In the US, Barry et al. also recognized the complexity of obesity policy support in their study, which used a nationally representative, adult sample through an online panel [21]. They attempted to address this complexity by sorting several potential causes of obesity into metaphorical framings. Metaphors are believed to be more than linguistic tools; they also sub-consciously influence how people experience and perceive the world [22]. Policy metaphors in particular are a model developed to explain how citizens, including the least and most politically informed, make sense of public affairs and social policy, in light of evidence that public opinion is divorced from conventional measures of political ideology [23,24]. Barry et al. obtained the metaphors for obesity from dialogue among influential public figures and then developed a list of seven metaphors using qualitative methods. These metaphors ranged from blaming individuals for being undisciplined and embodying the biblical taboos of sloth and gluttony (i.e., sinful behaviour) to blaming an environment that is ubiquitous with cheap, unhealthy foods (i.e., toxic food environment). Some metaphors also integrated facets of both individual choice and external forces to create metaphors of mixed blame, such as lacking the time to eat healthy and exercise (i.e., time crunch) where the blame may reside in poor personal priorities or workcentric societal norms. The metaphors served as a measure for the degree of individual controllability for causing obesity. Metaphors attributing obesity to uncontrollable factors were significant predictors of increased support for obesity policy relative to the metaphor that most emphasized controllable factors (i.e., sinful behaviour). This result concurs with the predictions of attribution theory. Still, the pattern by which the seven metaphors predicted policy support was more complex than simply less individual responsibility meaning more policy support. There may be other factors involved in affecting policy support outside of controllability of obesity.

\subsection{Individualism and Collectivism}

How people respond to controllability of obesity may 
be different depending on whether they live in an individualist or collectivist country. Individualist countries expect individuals to take care of themselves, whereas collectivist countries view individuals as part of a community where people can expect that others are looking out for them [25]. Individualist countries are more likely to commit the fundamental attribution error: a bias that attributes the behaviours of a person to the characteristics of that person instead of the situation or environment that person is in [26]. This error can transfer to attributions for obesity, and Crandall et al. demonstrated that individualist countries show a stronger tendency to harbour anti-fat prejudice when they hold individuals accountable for their weight [27]. In contrast, collectivist countries are less likely to link negative cultural values (being obese is bad) to the person (being an obese person is bad). There is a cultural component to blaming obese individuals that varies among countries. Crandall and Martinez found less anti-fat prejudice and fewer attributions of individual controllability in Mexico, a collectivist country, compared to the US, an individualist country [28]. Attribution theory suggests that obtaining support for constructive and non-oppressive obesity policies would be more difficult in individualist countries where people more commonly assign greater individual controllability of obesity. Conversely, garnering support for such obesity policy may be easier in collectivist countries where people are less likely to link obesity to individual controllability.

\subsection{National Identity}

The individualist versus collectivist classification may contribute to differences when comparing Canadian and US public perceptions of obesity policy. Canada and the US appear culturally similar on the exterior: 90 percent of Canadians live within 100 miles of the US-Canada border, so media and commerce is frequently exchanged [29]. Both countries share similar lifestyles of sedentary jobs, leisure, and transportation along with environments of aggressively marketed and abundant food, all of which are related to obesity [30]. However, as we discussed earlier for the $\mathrm{EU}$, there is national variation in obesity policy support among countries and this variation likely extends to Canada and the US National variation in obesity policy support may be explained through countryspecific factors with deep-seated origins in cultural and historical context, such as national identity. By national identity, we are referring to the beliefs and sentiments of citizens that result from identifying with the unique historical, economic, social, and cultural context of a country. The strength of national identity relates to the intensity of positive attachment for the nation [31]. National identity in Canada is associated with inclusive social policy, tolerance for multiculturalism and diversity, and perhaps most interestingly, differentiation from what constitutes an American [32,33]. Although Canada and the US are individualist countries, Canada may be distinguished from Americans in prescribing more to a collectivist social contract in terms of health (e.g., universal healthcare) $[34,35]$. The authors recognize that there is growing income inequality in Canada, as in much of the world, but the cultural values of Canada that form the collectivist bias are more ingrained, hardy, and constant than fluctuating economies [36]. These traditional Canadian values of tolerance, inclusion, and egalitarian healthcare may prompt Canadians with a strong sense of national identity to expect government involvement in helping the obese.

The objective of this study was to conduct the first Canadian study of young adults assessing support for different obesity policies, and to examine whether their beliefs about the causes of obesity affect their support for obesity policies. We were specifically interested in perceptions of young adult students because 1) they are future policy leaders of Canada; and 2) university campuses are centers for political activism [37]. To allow comparison with US findings, we replicated the methods reported by Barry et al. To extend their work, we explored whether national identity, which may also reflect a more collectivist orientation, was a unique predictor of policy support above and beyond the effect of individual responsibility.

\section{METHODS}

\subsection{Data Collection}

We used a modified form of the Yale Rudd Center Public Opinion on Obesity Survey that Barry et al. created and implemented. The survey was pre-tested on undergraduate and graduate students $(\mathrm{n}=6)$, and small changes in question wording were made based on feedback. We do not believe these changes to have affected the survey's reliability and validity, which was confirmed by Barry et al. We sampled from undergraduate students on the St. George campus at the University of Toronto. The survey was available between 9 January 2012-24 February 2012 using Qualtrics, an online survey interface. We provided access to the survey via website link printed on posters and flyers that we distributed throughout campus in study spaces, residence halls, classrooms, student group meetings, and eating spaces. There were 899 students who began the survey, and a 67 percent completion rate. There were 521 students who completed the survey and met the criteria of being full-time undergraduate students, and this sample was used for our analysis. The sample consisted of students from a broad variety of disciplines and year of study. Ethics approval for the study was obtained from the University Research 
Ethics Board, and all participants completed a consent form online prior to participating in the study.

\subsection{Measure: Obesity Policies}

The 17 obesity policies are those used by Barry et al. with some small changes in wording for clarification. One policy was split into two separate policies to avoid double-barrelled phrasing ("Provide individuals with tax credits for gym memberships or nutritional counselling"). Support for the policies was assessed on a five-point Likert scale $(1=$ strongly oppose, $5=$ strongly support $)$. For policies that would require an increase in taxes, questions were preceded with the condition: "For each of the following, please report if you would support the policy if it meant that once you graduate and get a job, you would need to pay an additional $\$ 50$ per year in taxes."

We conducted a factor analysis (available on request) to examine whether these policies grouped into similar clusters. Barry et al. reported three distinct factors: 1) redistributive policies, requiring an increase in taxes; 2) compensatory policies, directed toward helping or protecting society; and 3) price-raising policies, which increase the monetary costs of behaviours believed to lead to obesity. We also found these three factors in our factor analysis (using $>0.4$ factor loading), but some compensatory policies were more strongly loaded with the price-raising policy grouping. The insurance premiums policy was removed from the factor analysis and further inferential analysis because its support was highly correlated $(\mathrm{p}<0.05)$ with support for greater than 50 percent of the other policies. After removal of the premiums policy, the three policy groupings from the Barry et al. study had moderate to high internal reliability: Cronbach's alpha is 0.84 for redistributive policies, 0.70 for compensatory policies, and 0.78 for price-raising policies. Due to adequate internal reliability, and for the sake of replicability of Barry et al., this three-factor clustering model was used for analysis in this study.

\subsection{Measure: Obesity Metaphors}

Respondents were presented with seven paragraphs, with each paragraph corresponding to a particular metaphor (see Barry et al. for a detailed description of these metaphors). After each paragraph, the respondent was asked, "Out of every 100 Canadians with weight problems, for how many do you think that this account explains a lot about why they are overweight?" This phrasing permits respondents to exceed 100 as the total for all of the metaphors, meaning respondents can select multiple metaphors to explain why a single individual is obese. For statistical analysis, the metaphor responses were normed for each respondent to sum to exactly 100 so that the relative importance of each metaphor was standardized and comparable between respondents.

We conducted a factor analysis (available on request) to ensure that each metaphor was a distinct explanatory framing in the minds of the respondents. The results of our factor analysis were the same as those found by Barry et al. The sinful behaviour metaphor did not factor on its own but instead negatively loaded on all other factors. All metaphors other than sinful behaviour loaded highly and exclusively on separate factors (using $>0.4$ factor loading), so each metaphor was included as its own independent explanatory variable in statistical analyses.

\subsection{Measure: Canadian Identity}

Little agreement exists on how to conceptualize and measure national identity [31]. We have approached national identity through a framework of self-identity, defined as a salient part of an actor's self that relates to that behaviour [38]. We adopted items common to scales used to measure self-identity in previous studies that have incorporated self-identity into the Theory of Planned Behaviour. Although not originally a component of this theory, self-identity has been shown to be an independent and significant predictor of some behaviours, such as voting, exercise, and organic vegetable consumption [39-41]. For our study, Canadian identity was measured using a two-item assessment: "I think of myself as a Canadian" and "Being Canadian is an important part of who I am" [42]. Respondents were asked to rate their agreement on a six-point scale $(1=$ strongly disagree, $6=$ strongly agree). The two items had high internal reliability (Cronbach's alpha was 0.879 ), so they were summed to generate a scale ranging from 2 to 12 .

\subsection{Measure: Political Affiliation}

We assessed both political ideology and political party identification from respondents as potential explanatory variables. Respondents rated their political affiliation on a three-item scale as liberal, moderate, or conservative, and they selected their party identification as Liberal Party, Conservative Party, New Democratic Party, Bloq Quebecois, Green Party, or Other. The correlation between political ideology and political party identification was very strong $(\mathrm{p}<0.001)$, so only political ideology was used in statistical analyses.

\subsection{Measure: Demographics and Health Characteristics}

Demographic information was collected including gender, age, race, year at university, education of father and mother, and country of birth. The literature provides evidence that these demographics are predictors in varia- 
tions in health policy outcomes [21]. Education of mother and father was combined into a single term for regression analysis, using only the higher education attainment value of the two [43]. Health characteristics included self-reported health status (rated on a five-point scale including excellent, very good, good, fair, and poor) and self-reported moderate physical activity in bouts of 30 minutes or more (described as none, 1 - 2 times per week, 3 - 5 times per week, and 6 or more times per week). Moderate physical activity was defined for participants as "activity that raises your heart rate and breaks a sweat". For statistical analysis, self-reported physical activity was described in terms of those who did and did not meet the Canadian Physical Activity Guidelines for adults of at least 150 minutes of moderate- to vigorousintensity physical activity per week [44].

\subsection{Statistical Analysis}

Replicating the analytic approach reported by Barry et al., we used an ordinary least squares (OLS) regression to determine how demographics and health characteristics, political ideology, obesity metaphors, and Canadian national identity explained respondents' support for the obesity policies. The outcome variables were the three policy groupings (the support for all policies in each grouping was averaged), and for each policy grouping, the four predictors were included in the model in a hierarchical fashion. This method generated four models for each of the three policy groupings, resulting in 12 distinct regression outputs in total. This mode of analysis and the structural order to inserting the predictors is also a replication of the methodology of Barry et al.

\section{RESULTS}

\subsection{Descriptive Statistics}

Table 1 describes the descriptive statistics for the demographics, health characteristics, and political ideology of the respondents. The median age and percent female of our sample was 20 years and $61.5 \%$, respectively. This is broadly reflective of the University of Toronto undergraduate student population as a whole-median age of 20.9 years and $56.3 \%$ female [45].

Table 2 describes the frequency in which the respondents attributed obesity to each of the metaphors. A majority of the respondents found each metaphor to be an "important" explanation for obesity. Very few respondents found the metaphors to be "very important" explanations for obesity. Table 3 shows the frequency in which respondents endorsed multiple metaphors at once. We found that 94.0 percent of Canadians believed three or more of the metaphors to be "important", but only 2.5 to be "very important".

Table 4 describes the support for the obesity policies.
Table 1. Survey respondent characteristics.

\begin{tabular}{|c|c|c|}
\hline & acteristics & Frequency $(\%)$ \\
\hline \multicolumn{3}{|c|}{ Demographics } \\
\hline \multirow[t]{9}{*}{ Female } & & 65.1 \\
\hline & Age & \\
\hline & $\leq 17$ & 0.7 \\
\hline & 18 & 21.3 \\
\hline & 19 & 22.8 \\
\hline & 20 & 23.0 \\
\hline & 21 & 14.4 \\
\hline & 22 & 13.2 \\
\hline & $\geq 23$ & 4.6 \\
\hline
\end{tabular}

Race/ethnicity

White/non-Hispanic $\quad 41.1$

2.7

7.3

30.9

1.3

1.7

4.4

10.2

Education

\begin{tabular}{|c|c|}
\hline$<$ High school degree & 7.8 \\
\hline High school degree & 13.6 \\
\hline Some college & 18.4 \\
\hline Bachelor's degree or higher & 60.2 \\
\hline Born in Canada & 63.3 \\
\hline \multicolumn{2}{|l|}{ Health characteristics } \\
\hline $\mathrm{BMI}<25$ & 83.2 \\
\hline BMI 25 - 29 & 13.5 \\
\hline $\mathrm{BMI}>30$ & 3.3 \\
\hline \multicolumn{2}{|l|}{ Self-reported health } \\
\hline Excellent/very good & 51.4 \\
\hline Good & 35.7 \\
\hline Fair/poor & 12.9 \\
\hline \multicolumn{2}{|l|}{ Self-reported exercise level per week } \\
\hline $6+$ times per week & 9.8 \\
\hline $3-5$ times per week & 37.8 \\
\hline $1-2$ times per week & 38.2 \\
\hline None & 14.2 \\
\hline \multicolumn{2}{|l|}{ Political attitudes } \\
\hline \multicolumn{2}{|l|}{ Political ideology } \\
\hline Conservative & 12.9 \\
\hline Moderate & 39.1 \\
\hline Liberal & 48.0 \\
\hline
\end{tabular}


Table 2. Survey respondent beliefs about causes of obesity through metaphors.

\begin{tabular}{cccc}
\hline Obesity metaphor & $\begin{array}{c}\text { Degree of } \\
\text { individual } \\
\text { responsibility }\end{array}$ & $\begin{array}{c}\text { Important } \\
\text { explanation } \\
(\%)\end{array}$ & $\begin{array}{c}\text { Very important } \\
\text { explanation } \\
(\%)\end{array}$ \\
\hline $\begin{array}{c}\text { Sinful } \\
\text { behaviour } \\
\text { Addiction }\end{array}$ & $\begin{array}{c}\text { High individual } \\
\text { responsibility }\end{array}$ & 59.7 & 15.2 \\
Time crunch & 77.0 & 9.2 \\
$\begin{array}{c}\text { Eating disorder } \\
\text { Disability }\end{array}$ & 68.5 & 10.4 \\
$\begin{array}{c}\text { Industry } \\
\text { manipulation }\end{array}$ & 56.8 & 5.6 \\
$\begin{array}{c}\text { Toxic food } \\
\text { environment }\end{array}$ & $\begin{array}{c}\text { Low individual } \\
\text { responsibility }\end{array}$ & 87.9 & 3.3 \\
\hline
\end{tabular}

a"Important explanation" is defined as the survey respondent believing the metaphor to explain obesity in at least $10 \%$ of obese Canadians. "Very Important explanation" is defined as the survey respondent believing the metaphor to explain obesity in at least $25 \%$ of obese Canadians.
Table 3. Survey respondents identification with multiple metaphors.

\begin{tabular}{|c|c|}
\hline Number of metaphors & Frequency $(\%)$ \\
\hline \multicolumn{2}{|l|}{ Important explanations $^{\mathrm{a}}$} \\
\hline Identifying 1 to 2 metaphors as important & 6.0 \\
\hline Identifying 3 to 4 metaphors as important & 34.5 \\
\hline Identifying 5 to 7 metaphors as important & 59.5 \\
\hline \multicolumn{2}{|l|}{ Very important explanations ${ }^{b}$} \\
\hline Identifying 0 metaphors as very important & 51.6 \\
\hline Identifying 1 metaphor as very important & 29.6 \\
\hline Identifying 2 metaphors as very important & 16.3 \\
\hline Identifying $3+$ metaphors as very important & 2.5 \\
\hline
\end{tabular}

Table 4. Survey respondent support for obesity policies.

Redistributive policies

Support $(\%)^{\mathrm{a}}$

School lunches: Provide funding to elementary and secondary schools to make fresh fruit, vegetables, and low-fat milk available for free at school lunches.

Summer camps: Use government funds to establish a national network of summer camps for children that emphasizes good nutrition and exercise.

School concessions: Eliminate fast food and soda concessions from public schools and use government tax dollars to compensate the schools for the revenues they now make on these concessions.

Gym membership tax credit: Provide individuals with tax credits for gym memberships.

Treatment programs: Use government funds to establish rehabilitation programs for individuals struggling with their weight and modeled on treatment for other addictions, such as those for smoking or alcoholism.

Body-image campaign: Create a government-funded social marketing campaign to warn against the dangers of poor body image.

Worker paid time: Require that employers provide all workers with 30 minutes of paid time each day for physical activity, and have the Government subsidize the cost.

Nutritional counseling tax credit: Provide individuals with tax credits for nutrition counseling.

\section{Compensatory policies}

Zoning laws: Have zoning laws require that all new residential and commercial developments include sidewalks and other safe paths to encourage physical activity.

Food labeling: Require warning labels on foods with high-fat and/or high-sugar content, indicating that such foods may be addictive.

Trans fat food establishments: Require that restaurants and fast food establishments prepare their foods using oils free of trans fats, even if this drives up the costs of a meal.

Public-service announcements: Require television stations to provide free time for public service announcements on healthy eating and physical activity in equal proportion to the time spent on advertising for unhealthy foods and beverages.

Food advertising: Prohibit all advertising for high-fat and/or high-sugar foods on media watched primarily by children.

Anti-discrimination protections: Overweight people should be subject to the same legal protections and benefits offered to people with other physical disabilities.

\section{Price-raising policies}

Grocer surcharge: Require grocers to add a surcharge to high-fat and/or high-sugar foods and use the revenues to reduce their prices for fresh fruits and vegetables.

aSupport percent is defined as percentage of survey respondents who said they "strongly support" or "somewhat support" the policy. 
Table 5. OLS regression results for obesity policy groupings.

\begin{tabular}{|c|c|c|c|c|c|c|c|c|c|c|c|c|}
\hline & \multicolumn{4}{|c|}{ Redistributive policies } & \multicolumn{4}{|c|}{ Compensatory policies } & \multicolumn{4}{|c|}{ Price-raising policies } \\
\hline & 1 st & 2 nd & $3 \mathrm{rd}$ & 4th & 1 st & 2 nd & $3 \mathrm{rd}$ & 4th & 1 st & 2 nd & $3 r d$ & 4th \\
\hline \multicolumn{13}{|l|}{$\begin{array}{l}\text { Demographics } \\
\text { and health } \\
\text { characteristics }\end{array}$} \\
\hline \multirow[t]{2}{*}{ Female } & $0.362^{* * *}$ & $0.336^{* * *}$ & $0.241^{* * *}$ & $0.236^{* * *}$ & $0.368^{* * *}$ & $0.343^{* * *}$ & $0.237^{* * *}$ & $0.232^{* * *}$ & $0.341^{* * *}$ & $0.313^{* * *}$ & $0.231^{*}$ & $0.228^{*}$ \\
\hline & $(4.44)$ & $(4.20)$ & $(2.92)$ & $(2.89)$ & $(4.82)$ & $(4.61)$ & $(3.07)$ & $(3.04)$ & $(2.91)$ & $(2.70)$ & $(1.88)$ & $(1.86)$ \\
\hline \multirow[t]{2}{*}{ Age } & 0.025 & 0.016 & 0.017 & 0.014 & 0.006 & -0.003 & -0.003 & -0.006 & -0.018 & -0.026 & -0.026 & -0.028 \\
\hline & $(1.02)$ & $(0.69)$ & $(0.73)$ & $(0.61)$ & $(0.25)$ & $(0.13)$ & $(0.15)$ & $(0.28)$ & $(0.52)$ & $(0.76)$ & $(0.76)$ & $(0.80)$ \\
\hline \multirow[t]{2}{*}{ Non-white } & 0.102 & 0.112 & 0.068 & 0.095 & -0.038 & -0.021 & -0.054 & -0.028 & -0.158 & -0.151 & -0.145 & -0.131 \\
\hline & $(1.28)$ & $(1.44)$ & $(0.87)$ & $(1.24)$ & $(0.51)$ & $(0.29)$ & $(0.74)$ & $(0.39)$ & $(1.39)$ & (1.34) & $(1.26)$ & $(1.13)$ \\
\hline \multirow{2}{*}{$\begin{array}{l}\text { High school } \\
\text { diploma }\end{array}$} & $0.895^{* * *}$ & $0.882^{* * *}$ & $0.890^{* * *}$ & $0.846^{* * *}$ & 0.246 & 0.230 & 0.223 & 0.182 & 0.208 & 0.196 & 0.206 & 0.183 \\
\hline & $(3.85)$ & $(3.88)$ & $(3.96)$ & $(3.81)$ & $(1.13)$ & $(1.08)$ & $(1.07)$ & $(0.88)$ & $(0.62)$ & $(0.59)$ & $(0.62)$ & $(0.55)$ \\
\hline \multirow[t]{2}{*}{ Some university } & $0.689^{* * *}$ & $0.701^{* * *}$ & $0.703^{* * *}$ & $0.638^{* * *}$ & 0.182 & 0.186 & 0.188 & 0.126 & 0.129 & 0.146 & 0.155 & 0.122 \\
\hline & $(3.26)$ & $(3.39)$ & $(3.42)$ & $(3.14)$ & $(0.92)$ & $(0.97)$ & $(0.98)$ & $(0.66)$ & $(0.42)$ & $(0.49)$ & $(0.51)$ & $(0.40)$ \\
\hline \multirow{2}{*}{$\begin{array}{c}\text { Bachelor's } \\
\text { degree+ }\end{array}$} & $0.684^{* * *}$ & $0.674^{* * *}$ & $0.688^{* * *}$ & $0.665^{* * *}$ & 0.195 & 0.175 & 0.185 & 0.163 & 0.195 & 0.190 & 0.206 & 0.194 \\
\hline & (3.43) & $(3.45)$ & $(3.55)$ & (3.48) & $(1.04)$ & $(0.96)$ & $(1.02)$ & $(0.91)$ & $(0.68)$ & $(0.67)$ & $(0.71)$ & $(0.67)$ \\
\hline \multirow[t]{2}{*}{ BMI 25 - 29} & 0.131 & 0.179 & $0.190^{*}$ & 0.171 & 0.103 & 0.150 & $0.169^{*}$ & 0.151 & $0.288^{*}$ & $0.336^{* *}$ & $0.339^{* *}$ & $0.329^{* *}$ \\
\hline & $(1.14)$ & $(1.60)$ & $(1.73)$ & $(1.57)$ & $(0.96)$ & (1.44) & $(1.65)$ & $(1.48)$ & (1.76) & $(2.07)$ & $(2.07)$ & $(2.01)$ \\
\hline \multirow{2}{*}{$\mathrm{BMI} \geq 30$} & -0.051 & -0.092 & -0.131 & -0.114 & -0.191 & -0.233 & -0.284 & -0.268 & -0.291 & -0.331 & -0.334 & -0.325 \\
\hline & $(0.23)$ & $(0.43)$ & $(0.62)$ & $(0.55)$ & $(0.94)$ & (1.18) & $(1.45)$ & (1.39) & $(0.93)$ & $(1.08)$ & $(1.07)$ & $(1.04)$ \\
\hline \multirow[t]{2}{*}{ Good health } & $-0.151^{*}$ & -0.117 & -0.131 & -0.132 & -0.076 & -0.038 & -0.056 & -0.057 & $-0.247^{* *}$ & $-0.216^{*}$ & $-0.235^{*}$ & $-0.235^{*}$ \\
\hline & $(1.74)$ & $(1.38)$ & $(1.56)$ & $(1.60)$ & $(0.93)$ & $(0.48)$ & $(0.72)$ & $(0.74)$ & (1.98) & (1.74) & $(1.88)$ & (1.89) \\
\hline \multirow[t]{2}{*}{ Fair/poor health } & $-0.221^{*}$ & $-0.208^{*}$ & $-0.235^{* *}$ & -0.176 & $-0.367^{* * *}$ & $-0.355^{* * *}$ & $-0.368^{* * *}$ & $-0.311^{* * *}$ & $-0.422^{* *}$ & $-0.407^{* *}$ & $-0.421^{* *}$ & $-0.390^{* *}$ \\
\hline & $(1.80)$ & $(1.73)$ & (1.99) & $(1.50)$ & (3.19) & $(3.16)$ & (3.33) & $(2.83)$ & (2.39) & $(2.33)$ & $(2.39)$ & $(2.20)$ \\
\hline \multirow{2}{*}{$\begin{array}{l}\text { Below activity } \\
\text { guidelines }\end{array}$} & 0.168 & 0.125 & 0.036 & 0.010 & 0.116 & 0.064 & -0.051 & -0.075 & -0.288 & $-0.328^{*}$ & $-0.377^{*}$ & $-0.391^{* *}$ \\
\hline & $(1.27)$ & $(0.95)$ & $(0.27)$ & $(0.08)$ & $(0.93)$ & $(0.53)$ & $(0.41)$ & $(0.62)$ & $(1.51)$ & $(1.72)$ & $(1.92)$ & $(1.98)$ \\
\hline \multicolumn{13}{|l|}{$\begin{array}{c}\text { Political } \\
\text { attitudes }^{\text {b }}\end{array}$} \\
\hline \multirow[t]{2}{*}{ Moderate } & & $0.441^{* * *}$ & $0.384^{* * *}$ & $0.399^{* * *}$ & & $0.369^{* * *}$ & $0.320^{* * *}$ & $0.334^{* * *}$ & & $0.481^{* * *}$ & $0.435^{* *}$ & $0.443^{* *}$ \\
\hline & & $(3.72)$ & $(3.27)$ & $(3.44)$ & & $(3.34)$ & $(2.92)$ & (3.09) & & $(2.79)$ & $(2.49)$ & $(2.53)$ \\
\hline \multirow[t]{2}{*}{ Liberal } & & $0.598^{* * *}$ & $0.532^{* * *}$ & $0.518^{* * *}$ & & $0.579^{* * *}$ & $0.504^{* * *}$ & $0.491^{* * *}$ & & $0.609^{* * *}$ & $0.544^{* * *}$ & $0.537^{* * *}$ \\
\hline & & (5.13) & $(4.57)$ & $(4.51)$ & & $(5.33)$ & $(4.64)$ & $(4.58)$ & & $(3.59)$ & $(3.15)$ & $(3.11)$ \\
\hline \multicolumn{13}{|l|}{ Metaphors $^{\mathrm{c}}$} \\
\hline \multirow[t]{2}{*}{ Disability } & & & 0.005 & 0.005 & & & $0.009^{* *}$ & $0.009^{*}$ & & & 0.004 & 0.003 \\
\hline & & & $(1.04)$ & $(0.91)$ & & & $(2.00)$ & $(1.87)$ & & & $(0.50)$ & $(0.45)$ \\
\hline \multirow[t]{2}{*}{ Eating disorder } & & & $0.020^{* * *}$ & $0.019^{* * *}$ & & & $0.013^{* * *}$ & $0.012^{* *}$ & & & 0.009 & 0.008 \\
\hline & & & $(4.08)$ & $(3.76)$ & & & $(2.90)$ & $(2.56)$ & & & $(1.16)$ & (1.04) \\
\hline Addiction & & & 0.001 & 0.000 & & & 0.005 & 0.004 & & & 0.002 & 0.002 \\
\hline
\end{tabular}


Continued

\begin{tabular}{|c|c|c|c|c|c|c|c|c|c|c|c|c|}
\hline \multirow{3}{*}{ Time crunch } & & & $(0.29)$ & $(0.10)$ & & & $(1.17)$ & $(0.99)$ & & & $(0.30)$ & $(0.23)$ \\
\hline & & & $0.012^{* * *}$ & $0.011^{* *}$ & & & $0.010^{* *}$ & $0.009^{* *}$ & & & 0.001 & 0.000 \\
\hline & & & $(2.58)$ & $(2.50)$ & & & $(2.30)$ & $(2.21)$ & & & $(0.08)$ & $(0.04)$ \\
\hline \multirow{2}{*}{$\begin{array}{l}\text { Industry } \\
\text { manipulation }\end{array}$} & & & $0.009^{* *}$ & $0.010^{* *}$ & & & $0.009^{* *}$ & $0.009^{* *}$ & & & 0.000 & 0.000 \\
\hline & & & (2.18) & $(2.30)$ & & & $(2.10)$ & $(2.23)$ & & & $(0.02)$ & $(0.05)$ \\
\hline \multirow{2}{*}{$\begin{array}{l}\text { Toxic food } \\
\text { environment }\end{array}$} & & & $0.008^{*}$ & 0.007 & & & $0.013^{* * *}$ & $0.013^{* * *}$ & & & $0.014^{* *}$ & $0.014^{* *}$ \\
\hline & & & $(1.78)$ & (1.63) & & & (3.11) & $(2.97)$ & & & $(2.11)$ & $(2.05)$ \\
\hline \multirow[t]{2}{*}{$\begin{array}{c}\text { Canadian } \\
\text { identity }\end{array}$} & & & & $0.053^{* * *}$ & & & & $0.051^{* * *}$ & & & & 0.027 \\
\hline & & & & $(3.80)$ & & & & (3.89) & & & & $(1.30)$ \\
\hline R-squared & 0.074 & 0.120 & 0.165 & 0.189 & 0.067 & 0.119 & 0.161 & 0.185 & 0.051 & 0.074 & 0.083 & 0.087 \\
\hline
\end{tabular}

Note: Each pairing of numbers shows $\beta$ value and t statistic (below, in parenthesis); ${ }^{*}$ is $\mathrm{p}<0.10 ;{ }^{* *}$ is $\mathrm{p}<0.05 ;{ }^{* * *}$ is $\mathrm{p}<0.01$; ${ }^{\text {a }}$ The reference category for non-white is white; the reference category for parental education is less than high school diploma; the reference category for BMI is $<25$; the reference category for self-reported health is excellent/very good; the reference category for self-reported physical activity was meeting physical activity guidelines; ${ }^{\mathrm{b}}$ The reference category for political attitudes is conservative; ${ }^{\mathrm{c}}$ The reference category for metaphors is sinful behaviour.

The most uniform high support came for compensatory policies ( $>60$ percent), with the exception of anti-discrimination protection policy (18.6 percent). There was greater variety in support for the redistributive and priceraising policies, with the lowest in each category being nutritional counselling tax credits (41.8 percent) and insurance premiums (37.8 percent), respectively. The highest level of support for redistributive and price-raising policies, however, reached similar levels as the well-supported compensatory policies.

\subsection{Regression Statistics}

Table 5 shows the results of the OLS regression. Females were more likely to support all three policy groupings than males. Respondents whose parents had a high school diploma, some university, or at least a Bachelor's degree were more likely to support redistributive policies compared to those whose parents had less than a high school degree. Overweight respondents, but not obese respondents, showed increased support for price-raising policies relative to those having a BMI of less than 25 . Those in fair/poor health were less likely to support compensatory and price-raising policies compared with those in excellent/very good health. Liberals and moderates were more likely to support all three policy groupings compared to conservatives.

Some of the metaphors were able to predict variation in policy support. Three of the metaphors predicted greater support for both redistributive and compensatory policies: eating disorder, time crunch, and industry manipulation. The disability and toxic food environment metaphors also predicted increased support for compensatory polices. Toxic food environment was the only metaphor to be significantly correlated with price-raising policies.
In the final models, Canadian identity had explanatory power for redistributive and compensatory policy support beyond the variance explained by demographics and health, political attitudes, and causal metaphorical framings. Canadian identity was correlated with redistributive policy support $(\mathrm{p}<0.01)$, and the R-squared for the model including Canadian identity was noticeably greater (0.189) than the model including only demographics and health characteristics, political ideology, and metaphors (0.165). Canadian identity was also correlated with compensatory policy support $(\mathrm{p}<0.01)$, and the Rsquared for the model with Canadian identity (0.185) was also greater than the model without it $(0.161)$.

\section{DISCUSSION}

Canada's current focus on education and the individual have not been effective in combating obesity, and there has been little evidence suggesting that this approach will change in the future. Our study, however, provides novel insight into the feasibility of population-level policy among young adults, a population that is on the brink of starting to pay taxes and may already be voting for policies and elected officials (voting age in Canada is 18). Our results showed that there exists substantial support for a wide variety of obesity policies among young adults in Toronto, Canada. Compensatory policies were more consistently supported than redistributive policies, perhaps because compensatory policies do not require increasing taxes. Still, redistributive policies garnered high support if they sought to curb childhood obesity, such as more nutritious school lunches (78.9 percent), summer camps for healthy living (63.0 percent), and eliminating school concessions (58.0 percent). The high level of support for child-related obesity policies is supported by 
the literature [46], but there was also considerable support for policies affecting the adult population, such as zoning laws that encourage physical activity ( 77.7 percent), improved food labeling (66.6 percent), and grocer surcharges on unhealthy foods (63.0 percent). Redistributive and price-raising policies had moderate to high support for several of their policies, but they showed greater variability in support than compensatory policies. Toronto policy makers would likely find support for all three policy groupings among young adults, with compensatory policies being the most acceptable whereas restributive and price-raising policies may require greater advocacy to the public depending on the specific policy.

In comparison to the results reported by Barry et al. in the US, the respondents from our study showed greater support for 15 of the 17 policies, with the exceptions being nutritional counselling tax credits and anti-discrimination protection policy. Support for the anti-discrimination policy was the lowest and it stands in contrast to the other compensatory policies, likely due to the wording of the policy that indirectly claims obesity is a "disability". Discrimination policy specifically for weight does not exist in Canada or the US, so legal recourse is often sought instead through clauses that protect people with physical disabilities [47]. Reluctance to describe obesity as a disability is also apparent in that the disability metaphor was the least endorsed metaphor in our study, a result that is common in the literature [48]. Overall, these findings suggest that the potential for obesity policy support among Canadian young adults may be greater than support among the general population in the US. A more direct comparison between equivalent or matched populations of Canada and the US would more solidly support this statement, and it is a limitation of our study that our results cannot necessarily be generalized beyond the perceptions of young Toronto adults in university.

The demographics for determining obesity policy support, much less policy support in general, are understudied and sometimes contradictory in the literature. Our study found significance in several variables for predicting policy support in the OLS regression that were nonsignificant in the study by Barry et al.: being female and price-raising policies, having a high school diploma or some university education and redistributive policies, being overweight and price-raising policies, having fair/ poor health and compensatory and price-raising policies, and being moderate or liberal and price-raising policies. Some of these trends are apparent in literature for policy in other health domains, such as tobacco policy, where females, higher educational attainment, and liberal ideology are indicative of greater policy support [49,50]. Perhaps most surprising is that overweight respondents were more likely to support price-raising policies that financially punish the obese, although it is notable that this association did not exist for obese respondents. Overweight respondents may feel more empowered to cease obesity-related behaviour when there is a financial incentive, whereas obese individuals may feel unfairly discriminated for behaviours that have become routine parts of their lives.

The most commonly endorsed metaphors were those corresponding to moderate and low individual responsibility, with respondents showing greatest approval of more external metaphors such as toxic food environment, industry manipulation, addiction, and time crunch. There was also wide endorsement of five to seven metaphors as "important" explanations of obesity, showing that the respondents were aware of the complexity and multicausal nature of obesity. The metaphors in our study showed weaker and limited explanatory power in the OLS regression for obesity policy support in comparison to the results of Barry et al. In both our study and the US study, nearly all metaphors showed predictive power for redistributive and compensatory policies compared to the sinful behaviour metaphor, although the significance was greater for the US study (i.e., more than twice as many metaphors were significant at the 0.01 level). This finding shows that there is a correlation between individual responsibility for obesity and policy support in our sample, but that it may not be as prominent as in the US For the price-raising policies, the US study found a negative association with three metaphors (disability, eating disorder, and addiction) relative to sinful behaviour, whereas our study's results found a positive association with one metaphor (toxic food environment). A positive association between price-raising policies and toxic food environment is surprising given that these policies fault the individual whereas this metaphor does not. Price-raising policies, particularly taxes on unhealthy foods, may be viewed by the respondents as creating an environment of relatively inexpensive, healthy foods that the obese will purchase in place of unhealthy foods rather than viewing these policies as penalizing obese individuals who will continue to buy unhealthy foods.

Possibly reflecting a collectivist orientation, Canadian national identity was able to explain some of the complexity in predictors for obesity policy support beyond attribution theory. The OLS regression showed that $\mathrm{Ca}$ nadian identity had explanatory power in predicting increased support for redistributive and compensatory policies above and beyond not only the metaphors, our measure for individual controllability of obesity, but also demographics, health characteristics, and political ideology. This association between national identity and obesity policy support is a novel finding that may partially explain differences in policy support for obesity among countries. National identity is worthy of consideration in 
affecting obesity policy support perhaps due to its reflection of social and cultural norms [51]. Some of these norms may be related to expectations of individuals to regulate their health and weight, but the influence of national identity could extend into other beliefs and ideologies that affect obesity policy support. Hilbert et al. found that residence in the eastern and formerly socialist region of Germany correlated with greater support for obesity policy [52]. Anti-fat bias has been shown to be linked to a belief in a just world, Protestant work ethic, authoritarianism, and political conservatism [53]. The relationship of these components to national identity and obesity policy support are worthy of exploration in future studies.

In considering our findings, there were several limitations, such as our study's focus on young adults at the University of Toronto. We recognize that using a convenience sample limits the generalizability of the data. Additionally, a large percentage of variance remained unexplained in relation to policy support in the OLS regressions, so there are other factors beyond the variables we measured that influence obesity policy support. Our study included the variables used by Barry et al. which have been shown in other studies to be associated with support for health policy. Our measures for health characteristics were all self-reported, so there is the potential for bias to skew the information (e.g., understating weight). However, self-reporting is a cost-efficient and common method of collecting health data, and we have no reason to believe our data are skewed more or less than any other health-related survey. The measure of Canadian identity was also blunt, and we can only speculate about how identifying as Canadian influences policy support. However, there is not a standard measure for determining national identity, and this is the first study to explore the relationship between Canadian national identity and policy support.

\section{CONCLUSIONS}

Our study demonstrates that there may be high recaptiveness to obesity policy among young adults. This is an optimistic result for those wishing to shift Canada's current approach to obesity from education and individual behaviour change to population-level policies and an emphasis on upstream structural factors. This finding needs confirmation in larger, representative surveys of the $\mathrm{Ca}$ nadian population. Future studies should seek to determine support for obesity in Toronto and the rest of Canada among populations other than students and at the local, provincial, and national levels.

The effect of national identity on obesity policy support has not been studied. Given variation in national levels of support for different types of policy [9], our findings suggest assessing national identity might be a useful addition for researchers in understanding such variation and exploring the transferability of policies across national borders. Defining which factors of national identity are relevant could be realized through comparesons in a multi-country study. Further exploration of national identity, in Canada and elsewhere, has implications for understanding obesity policy support that might assist policy makers to make more informed decisions in how they address obesity in their communities.

\section{ACKNOWLEDGEMENTS}

This work was funded by the J. William Fulbright Fellowship and Fulbright Canada. Thanks to Agnes Hsin and Vivien Li for their assistance in poster and leaflet distribution of the survey. Thanks to Scott Leatherdale, Elizabeth Barden, and Michael Diamond for their feedback on survey wording and formatting.

\section{REFERENCES}

[1] Statistics Canada (2010) Body mass index, overweight or obese, self-reported, adult, by age group and sex. Canadian Community Health Survey.

http://www.statcan.gc.ca/tables-tableaux/sum-som/101/cst 01/health81b-eng.htm

[2] Statistics Canada (2010) Body mass index, changes from $1994 / 1995$ to $2004 / 2005,2006 / 2007$ and $2008 / 2009$, by sex. Canadian Community Health Survey. http://www.statcan.gc.ca/tables-tableaux/sum-som/101/cst 01/hlth68-eng.htm

[3] Marinou, K., Tousoulis, D., Antonopoulos, A.S., Stefanadi, E. and Stefanadis, C. (2010) Obesity and cardiovascular disease: From pathophysiology to risk stratification. International Journal of Cardiology, 138, 3-8. doi:10.1016/j.ijcard.2009.03.135

[4] Kolotkin, R.L., Meter, K. and Williams, G.R. (2001) Quality of life and obesity. Obesity Reviews, 2, 219-229. doi:10.1046/j.1467-789X.2001.00040.x

[5] Anis, A.H., Zhang, W., Bansback, N., Guh, D.P., Amarsi, Z. and Birmingham, C.L. (2010) Obesity and overweight in Canada: An updated cost-of-illness study. Obesity Reviews, 11, 31-40. doi:10.1111/j.1467-789X.2009.00579.x

[6] Alvaro, C., Jackson, L.A., Kirk, S., McHugh, T.L., Hughes, J., Chircop, A. and Lyons, R.F. (2011) Moving Canadian government policies beyond a focus on individual lifestyle: Some insights from complexity and critical theories. Health Promotion International, 26, 91-99. doi:10.1093/heapro/daq052

[7] Prince, S.A. (2009) A population health approach to obesity in Canada-Putting the problem back into context. Transdisciplinary Studies in Population Health Series, 1, 22-33.

[8] Mello, M.M., Studdert, D.M. and Brennan, T.A. (2006) Obesity-The new frontier of public health law. New England Journal of Medicine, 354, 2601-2610. doi:10.1056/NEJMhpr060227

[9] Suggs, L.S. and McIntyre, C. (2011) European Union 
public opinion on policy measures to address childhood overweight and obesity. Journal of Public Health Policy, 32, 91-106.

[10] Morin, P. and Marie-Andrée, R. (2011) Perceptions of employed parents about early childhood obesity and the need for prevention strategies. Health Promotion Practice, $1-9$.

[11] Potestio, M.L., McLaren, L., Vollman, A.R. and DoyleBaker, P.K. (2008) Childhood obesity: Perceptions held by the public in Calgary, Canada. Canadian Journal of Public Health, 99, 86-90.

[12] Heider, F. (1958) The psychology of interpersonal relations. Lawrence Erlbaum Associates, Hillsdale. doi:10.1037/10628-000

[13] Gilbert, D.T. and Malone, P.S. (1995) The correspondence bias. Psychological Bulletin, 117, 21-38. doi:10.1037/0033-2909.117.1.21

[14] Niederdeppe, J., Robert, S.A. and Kindig, D.A. (2011) Qualitative research about attributions, narratives, and support for obesity policy. Preventing Chronic Disease, 8 , $1-8$.

[15] Weiner, B. (1993) On sin versus sickness: A theory of perceived responsibility and social motivation. American Psychologist, 48, 957-965. doi:10.1037/0003-066X.48.9.957

[16] Oliver, J.E. and Lee, T. (2005) Public opinion and the politics of obesity in America. Journal of Health Politics and Law, 30, 923-954. doi:10.1215/03616878-30-5-923

[17] Pellegrini, R.J., Queirolo, S.S., Monarrez, V.E. and Valenzuela, D.M. (1997) Political identification and perceptions of homelessness: Attributed causality and attitudes on public policy. Psychological Reports, 80, 11391148. doi:10.2466/pr0.1997.80.3c.1139

[18] Hawkins, D.F. (1981) Causal attribution and punishment for crime. Deviant Behavior, 2, 207-230. doi:10.1080/01639625.1981.9967554

[19] Seacat, J.D., Hirschman, R. and Mickelson, K.D. (2007) Attributions of HIV onset controllability, emotional reactions, and helping intentions: Implicit effects of victim sexual orientation. Journal of Applied Social Psychology, 37, 1442-1461. doi:10.1111/j.1559-1816.2007.00220.x

[20] Chambers, S.A. and Traill, W.B. (2011) What the UK public believes causes obesity, and what they want to do about it: A cross-sectional study. Journal of Public Health Policy, 32, 430-444. doi:10.1057/jphp.2011.45

[21] Barry, C.L., Brescoll, V.L., Brownell, K.D. and Schlesinger, M. (2009) Obesity metaphors: How beliefs about the causes of obesity affect support for public policy. Milbank Quarterly, 87, 7-47. doi:10.1111/j.1468-0009.2009.00546.x

[22] Lakoff, G. and Johnson, M. (1980) Metaphors we live by. University of Chicago Press, Chicago.

[23] Schlesinger, M., and Lau, R.R. (2000) The meaning and measure of policy metaphors. American Political Science Review, 94, 611-626. doi:10.2307/2585834

[24] Lau, R.R. and Schlesinger, M. (2005) Policy frames, metaphorical reasoning, and support for public policies. Political Psychology, 26, 77-114. doi:10.1111/j.1467-9221.2005.00410.x

[25] Singelis, T.M., Triandis, H.C., Bhawuk, D.P.S. and Gelfand, M.J. (1995) Horizontal and vertical dimensions of individualism and collectivism: A theoretical and measurement refinement. Cross-Cultural Research, 29, 240275. doi:10.1177/106939719502900302

[26] Lee, F., Hallahan, M. and Herzog, T. (1996) Explaining real-life events: How culture and domain shape attributions. Personality and Social Psychology Bulletin, 22, 732-741. doi:10.1177/0146167296227007

[27] Crandall, C.S., D’Anello, S., Sakalli, N., Lazarus, E., Nejtardt, G.W. and Feather, N.T. (2001) An attributionvalue model of prejudice: Anti-fat attitudes in six nations. Personality and Social Psychology Bulletin, 27, 30-37. doi: $10.1177 / 0146167201271003$

[28] Crandall, C.S. and Martinez, R. (1996) Culture, ideology, and antifat attitudes. Personality and Social Psychology Bulletin, 22, 1165-1176. doi:10.1177/01461672962211007

[29] Coates, K. (2000) Cyber-Canada: Electronic commerce and Canadian life. International Communication Gazette, 62, 301-317. doi:10.1177/0016549200062003008

[30] French, S.A., Story, M. and Jeffery, R.W. (2001) Environmental influences on eating and physical activity. Annual Review of Public Health, 22, 309-335. doi:10.1146/annurev.publhealth.22.1.309

[31] Carey, S. (2002) Undivided loyalties: Is national identity an obstacle to European integration? European Union Politics, 3, 387-413. doi:10.1177/1465116502003004001

[32] MacGregor, R.M. (2003) I am Canadian: National identity in beer commercials. The Journal of Popular Culture, 37, 276-286. doi:10.1111/1540-5931.00068

[33] Lee, J.W. and Hébert, Y.M. (2006) The meaning of being Canadian: A comparison Between youth of immigrant and non-immigrant origins. Canadian Journal of Education, 29, 497-520. doi:10.2307/20054174

[34] Hofstede, G. (1980) Culture's consequences: International differences in work-related values. Sage Publications, Newbury Park.

[35] Resnick, P. (2005) The European roots of Canadian identity. Broadview Press, Toronto.

[36] Fortin, N.M., Green, D.A., Lemieux, T., Milligan, K. and Riddell, W.C. (2012) Canadian inequality: Recent developments and policy options. Canadian Public Policy, 8, 121-145. doi:10.3138/cpp.38.2.121

[37] Thorne, A. (2010) Beating the apple tree: How the university coerces activism. Academic Questions, 23, 212224. doi:10.1007/s12129-010-9163-1

[38] Conner, M. and Armitage, C.J. (1998) Extending the theory of planned behavior: A review and avenues for further research. Journal of Applied Social Psychology, 28, 1429. 1464. doi:10.1111/j.1559-1816.1998.tb01685.x

[39] Granberg, C. and Holmberg, S. (1990) The intention-behavior relationship among US and Swedish voters. Social Psychology Quarterly, 53, 44-54. doi:10.2307/2786868

[40] Theodorakis, Y. (1994) Planned behaviour, attitude strength, role identity, and the prediction of exercise behavior. The 
Sport Psychologist, 8, 149-165.

[41] Sparks, P. and Shepherd, R. (1992) Self-identity and the theory of planned behavior: Assessing the role of identification with "green consumerism." Social Psychology Quarterly, 55, 388-399. doi:10.2307/2786955

[42] Hagger, M.S. and Chatzisarantis, N.L.D. (2006) Selfidentity and the theory of planned behaviour: Betweenand within-participants analyses. British Journal of Social Psychology, 45, 731-757. doi:10.1348/014466605X85654

[43] Miller, K.E., Barnes, G.M., Melnick, M.J., Sabo, D.F. and Farrell, M.P. (2002) Gender and racial/ethnic differences in predicting adolescent sexual risk: Athletic participation versus exercise. Journal of Health and Social Behavior, 43, 436-450. doi: $10.2307 / 3090236$

[44] Canadian Society for Exercise Physiology (2011) Canadian physical activity guidelines. http://www.csep.ca/guidelines

[45] University of Toronto (2011) University of Toronto facts and figures: Part D, students. http://www.utoronto.ca/_ shared/assets/UofT_2011_Fact sFiguresReport_D4488.pdf

[46] Evans, W.D., Finkelstein, E.A., Kamerow, D.B. and Renaud, J.M. (2005) Public perceptions of childhood obesity. American Journal of Preventive Medicine, 28, 26-32. doi:10.1016/j.amepre.2004.09.008

[47] Luther, E. (2010) Justice for all shapes and sizes: Com- batting weight discrimination in Canada. Alberta Law Review, 48, 167-188.

[48] Puhl, R.M. and Heuer, C.A. (2010) Public opinion about laws to prohibit weight discrimination in the United States. Obesity, 19, 74-82. doi:10.1038/oby.2010.126

[49] Hamilton, W.L., Biener, L. and Rodger, C.N. (2005) Who supports tobacco excise taxes? Factors associated with towns' and individuals' support in Massachusetts. Journal of Public Health Management and Practice, 11, 333-340.

[50] Cohen, J.E., de Guia, N.A., Ashley, M.J., Ferrence, R., Northrup, D.A. and Studlar, D.T. (2002) Predictors of Canadian legislators' support for tobacco control policies. Social Science and Medicine, 55, 1069-1076. doi:10.1016/S0277-9536(01)00244-1

[51] Keillor, B.D. and Hult, G.T.H. (1999) A five country study of national identity: Implications for international marketing research and practice. International Marketing Review, 16, 65-82. doi:10.1108/02651339910257656

[52] Hilbert, A., Rief, W. and Braehler, E. (2007) What determines public support of obesity prevention? Journal of Epidemiology and Community Health, 61, 585-590. doi:10.1136/jech.2006.050906

[53] Crandall, C.S. (1994) Prejudice against fat people: Ideology and self-interest. Journal of Personality and Social Psychology, 66, 882-894. doi:10.1037/0022-3514.66.5.882 